\title{
Os anos Jango e a questão democrática
}

Marly Silva da Motta*

\section{Resumo}

A partir do reconhecimento da extensão e profundidade da construção democrática realizada no Brasil entre 1945 e 1964, busco analisar algumas características específicas dessa construção, focando, especialmente, o período de governo do presidente João Goulart (set.1961/mar.64). Defendo a hipótese de que as várias feições da questão democrática nesse período tiveram um papel crucial na maneira como se desenrolou o golpe que encerrou o regime democrático e instituiu a ditadura no país.

\section{Palavras-chave}

Questão democrática. Anos Jango. Golpe de 64.

\section{Abstract}

Since the recognition of the extent and depth of democratic construction carried out in Brazil between 1945 and 1964, this paper analyzes some specific features of this construction, focusing especially on the period that Joao Goulart (set.1961 /mar.64 ) was president. The hypothesis presented is that various aspects of democratic issue had an important role in the way the military coup took place, ending with the democratic regime and establishing a dictatorship in the country.

\section{Keywords}

Democratic Issue. Jango years. 64's coup.

\section{Introdução}

Relembrar os 50 anos do golpe de 1964 traz à baila um debate sobre o caráter da democracia brasileira. "Jovem”, "planta frágil, de difícil adaptação ao solo do país", são algumas das expressões utilizadas para qualificar as experiências democráticas do passado, e mesmo a do presente, em curso desde 1985. O

\footnotetext{
* Doutora em História pela Universidade Federal Fluminense (UFF) e professora do Curso Intensivo de Pós-Graduação em Administração Pública (Cipad) da Fundação Getúlio Vargas (FGV). E-mail: marly.motta@fgv.br.
} 
objeto deste texto é uma dessas experiências, aquela que abrange o período entre 1945 - quando se encerrou o Estado Novo, de Getúlio Vargas - e 1964. A partir do reconhecimento da extensão e profundidade da construção democrática realizada no Brasil entre 1945 e 1964, busco analisar algumas características específicas dessa construção, focando, especialmente, o período de governo do presidente João Goulart (setembro de 1961 / março de 1964).

Meu interesse pelo que eu chamo de questão democrática nos "anos Jango" foi despertado pelos trabalhos que realizei de revisão técnica e de redação da apresentação do livro 1964: o golpe que derrubou um presidente, pôs fim ao regime democrático e instituiu a ditadura no Brasil, de Jorge Ferreira e Angela de Castro Gomes. A leitura cuidadosa de 1964 me fez levantar a hipótese de que as várias feições da questão democrática no período Goulart tiveram um papel crucial na maneira como se desenrolou o golpe que encerrou o regime democrático e instituiu a ditadura no país.

Espremida entre duas ditaduras, a vivência democrática experimentada a partir de quatro sucessivas eleições presidenciais - 1945, 1950, 1955 e 1960 foi chamada, por vários estudiosos, de "República populista". Segundo essa interpretação, o "golpe militar" resultaria do fracasso dos "líderes populistas", em especial João Goulart, de conduzir a bom termo a participação das massas populares ao processo político. Por isso, tais lideranças teriam sido as maiores "responsáveis" pela incapacidade da sociedade brasileira de resistir à ditadura e se tornar uma "verdadeira democracia".

Contrários a essa corrente, vários historiadores, dentre os quais se destacam Angela de Castro Gomes e Jorge Ferreira, reconhecem o valor da experiência brasileira na construção de uma democracia nesse período, entrevistos na regularidade do processo eleitoral e na livre atuação de partidos políticos. Por exemplo, o Partido Comunista, embora na ilegalidade, se fazia representar em várias agremiações partidárias e tinha presença marcante na vida sindical. Mais importante, no entanto, foi o reconhecimento do povo como ator político a ser conquistado e incorporado ao regime democrático representativo, que levou até mesmo os políticos menos calejados no trato com as camadas populares a se obrigarem a rever suas estratégias de aproximação com os trabalhadores, o que requereu um aprendizado nada desprezível.

No entanto, o fato de ser reconhecido o estatuto de democracia para o período em tela, não nos exime de responder a várias perguntas, as quais, no fundo, visam a responder, enfim, que democracia era aquela. Que limites e possibilidades eram postos aos atores políticos, especialmente aos militares? 
Como se relacionavam os três poderes? Como funcionavam os partidos políticos? Qual o papel do presidente Goulart como líder e/ou mediador dos conflitos em jogo? Que apostas eram feitas na manutenção do regime democrático ou na sua derrubada?

\section{O papel político do Supremo Tribunal Federal (ou a falta dele)}

A presença hoje capilar do Judiciário não tem paralelo na história. Os litígios encontram formas de solução, reguladas pelas leis ${ }^{1}$.

(Luiz Werneck Vianna)

Um dos eventos mais marcantes da democracia brasileira foi a operação política que resultou no impeachment de Fernando Collor, em 1992. O processo que comandou o afastamento do primeiro presidente eleito diretamente, depois do jejum de 29 anos (1960-89) imposto pela ditadura, colocou em cena o protagonismo político do Poder Judiciário, em especial do Supremo Tribunal Federal (STF). Se alguns ainda recorreram a membros das Forças Armadas como uma possível força de moderação/pressão/intervenção em prol de uma solução cirúrgica mais rápida - a favor ou contra a permanência do presidente ${ }^{2}$-, é certo que a opção política vitoriosa foi aquela que previa o estrito cumprimento das normas constitucionais aprovadas há apenas quatro anos, em 1988.

A comparação com os procedimentos adotados por ocasião da renúncia de Jânio Quadros, em 25 de agosto de 1961, é inevitável. Menos do que indagar sobre os "reais" motivos que levaram o presidente a tomar essa medida extrema, me interessa perguntar sobre as razões do silêncio do STF que, em momento algum, foi provocado, como guardião da Constituição, a determinar os trâmites legais que presidiriam a posse do então vicepresidente, João Goulart, então em viagem no exterior.

Uma análise mais ampla desse tenso período entre 25 de agosto e 7 de setembro, quando Goulart tomou posse sob o regime parlamentarista,

\footnotetext{
${ }^{1}$ Luiz Werneck Viana, Revista Época, 31 de março de 2014.

${ }^{2}$ Ver: Gláucio Ary Dillon Soares; Maria Celina D’Araújo; e Celso Castro. A volta aos quartéis: a memória militar sobre a ditadura. Rio de Janeiro, Editora FGV, 1995.
} 
demonstra, por outro lado, o papel de protagonistas que os militares exerceram ao longo de todo esse processo. A começar pela iniciativa de se formar uma Junta Militar, composta pelos ministros da Guerra (hoje, Exército), Marinha e Aeronáutica, a qual, na prática, se legitimava para mandar no país. Apesar de o presidente da Câmara, deputado Ranieri Mazzilli, assumir a presidência da República, não hesitou em comunicar que a Junta Militar manifestara a "inconveniência” do regresso ao país do vice-presidente e, sobretudo, de sua posse como presidente da República, chegando a sugerir a possibilidade de sua prisão assim que desembarcasse no país. ${ }^{3}$ Foi também aos militares, os ditos "legalistas", que Jango e seu cunhado, o governador do Rio Grande do Sul, Leonel Brizola, recorreram para garantir a posse do vice no lugar do presidente que renunciara. ${ }^{4}$

Ao contrário do Judiciário, mantido à margem de toda a difícil negociação que resultaria na adoção do parlamentarismo, o Legislativo teve um papel de destaque na condução das propostas em jogo. Manifestou-se firmemente a favor da ordem constitucional, rejeitou a intimidação militar, e apoiou a posse de Jango. Na sessão parlamentar de 29 de agosto, a proposta de impeachment de Goulart foi derrotada por um placar acachapante: 299 votos contra e apenas 14 a favor. Mesmo a UDN, desalojada do poder com a renúncia de Jânio, defendeu o mandato de seu adversário que, como se sabe, era o principal líder do PTB.

O Supremo tampouco foi chamado a avaliar a constitucionalidade da implantação do regime parlamentarista como condição para a ascensão de Jango ao cargo de presidente da República. Feita uma nova redação na emenda que tramitava no Congresso havia muitos anos, sem ser levada a sério, a Emenda Constitucional n. 4, que instituiu o parlamentarismo no Brasil, foi aprovada em 2 de setembro por 233 votos contra $55 .^{5}$

A ausência do Judiciário pode ser mais uma vez notada no conflito entre os dois poderes - Executivo e Legislativo - em torno da aprovação do plebiscito

\footnotetext{
${ }^{3}$ Ver: Jorge Ferreira e Angela de Castro Gomes. 1964: o golpe que derrubou um presidente pôs fim ao regime democrático e instituiu a ditadura no Brasil. Rio de Janeiro, Civilização Brasileira, 2014, p. 436.

${ }^{4}$ Sobre a campanha da legalidade liderada por Brizola e a posição do comandante do III Exército a favor da posse de Goulart, ver, entre outros: Jorge Ferreira. "A legalidade traída: os dias sombrios de agosto e setembro de 1964". In: Jorge Ferreira; O imaginário trabalhista. Rio de Janeiro, Civilização Brasileira, 2005, p. 277-318.
}

${ }^{5}$ Ver Jorge Ferreira e Angela de Castro Gomes, op. cit., p. 45. 
com vistas a um possível retorno do regime presidencialista. O artigo n. 25 da Emenda parlamentarista previa a realização de uma consulta ao eleitorado sobre a continuidade do regime ou a volta do presidencialismo. A questão era o prazo para a convocação: nove meses antes do fim do mandato de Jango, o que, na prática, significaria amarrar as mãos do presidente.

A correlação de forças que se estabeleceu naquele momento em torno da convocação do plebiscito pode provocar alguma surpresa. Os ministros militares, indicando a divisão existente nas Forças Armadas desde 1961, pediram a antecipação do plebiscito, e receberam o apoio do movimento sindical. Pressionado pelo Executivo, e apesar de os principais partidos simpatizarem com a possibilidade de volta do presidencialismo, o Congresso não quis, voluntariamente, abandonar um regime que lhe garantia poderes excepcionais.

A falta de protagonismo político conferido ao Supremo nessa construção democrática do pós-1946 desembocou, em setembro de 1962, em uma grave crise político-militar. Uma carta dos chefes do I, II e III Exércitos ao presidente Goulart, com cópias para o primeiro-ministro, Brochado da Rocha, e para o ministro da Guerra, Nelson de Melo, anunciava que o Exército não defenderia o Legislativo no caso de "o povo se insurgir contra o fato de o Congresso recusar o plebiscito. O povo é soberano no regime democrático". ${ }^{6}$

Esse conflito entre o Executivo e Legislativo evidencia, a meu ver, uma dupla questão. A primeira se relaciona com determinadas concepções de regime democrático e soberania popular que não reconhecem a representação parlamentar como capaz de legitimamente se pronunciar sobre o sistema de governo. Negar ao povo o direito de se manifestar diretamente seria o equivalente a "abominar ou destruir" a experiência democrática em curso, mesmo que o dito "respeito à vontade popular" mal encobrisse a possibilidade de um golpe militar contra o Congresso.

O segundo ponto, igualmente relevante para a sustentação de nossa hipótese de trabalho, é o não reconhecimento do Judiciário como guardião da Constituição, embora previsto na Carta de 1946 e, em decorrência, a rejeição dos outros dois poderes, o Executivo e o Legislativo, em recorrer ao Supremo na questão da antecipação do plebiscito. Mais uma vez, foram

\footnotetext{
${ }^{6}$ Citado em Jorge Ferreira e Angela de Castro Gomes, op. cit., p. 115, grifos nossos.
} 
os militares que se apresentaram como o fiel da balança; só que, em 1962, ao contrário de um ano atrás, a posição vencedora foi a do apoio à volta do presidencialismo.

O presidente Goulart não apoiou a solução golpista indicada pelos chefes militares, e o Congresso foi preservado. ${ }^{7}$ Negociou a flexibilização da Emenda parlamentarista e jogou o plebiscito para janeiro de 1963. Desse modo, ainda teria três anos para governar e encaminhar a sua sucessão. Ficou evidente, também, que Jango possuía um dispositivo militar poderoso, de cunho nacionalista de esquerda, pronto a desfechar um golpe com o fechamento do Congresso.

Talvez o caso mais emblemático de desrespeito às decisões do Supremo tenha sido o julgamento do processo referente ao pedido de direitos políticos dos sargentos, uma vez que a Constituição de 46 permitia interpretações divergentes. Aliás, por essas brechas, em 1962, vários sargentos haviam sido eleitos prefeitos, vereadores e deputados. No dia 11 de setembro de 1963, o STF se manifestou contra o direito dos sargentos de concorrer a cargos eletivos. No lugar do hoje conhecido refrão de que "decisão do Supremo não se discute; cumpre-se”, houve reações contrárias à palavra do órgão máximo do Poder Judiciário.

Foi alto o preço pago pela democracia por esse episódio, que evidenciou a incapacidade do Judiciário de atuar como um ator de relevo no instável cenário político daquele momento. A resposta dos sargentos, tirada em uma assembleia em Brasília, foi um levante militar: tomaram pontos estratégicos da capital, inclusive a Base Aérea e o Ministério da Marinha, além de invadir a Câmara dos Deputados e o STF, prendendo seus respectivos presidentes. Jango, na Guanabara, e o ministro do Exército ficaram fora do domínio dos rebelados, e a pronta reação oficial conseguiu sufocar a rebelião com pequenas baixas humanas. ${ }^{8}$

As baixas políticas, no entanto, foram enormes. Vários analistas do período reconhecem que esse foi o momento a partir do qual a oposição a Goulart, especialmente representada pelas direitas, vislumbrou a possibilidade de reverter o jogo; ou seja, se apoderar da bandeira da democracia e lançar

\footnotetext{
${ }^{7}$ Ver Jorge Ferreira e Angela de Castro Gomes, op. cit., p. 121-22.

${ }^{8}$ Para uma análise detalhada da revolta dos sargentos, ver, entre outros: Paulo Parucker. Praças em pé de guerra. O movimento político dos subalternos militares no Brasil, 1961-64. Dissertação de Mestrado defendida no Programa de Pós-graduação em História (PPGH) da Universidade Federal Fluminense (UFF). Niterói, Rio de Janeiro, 1992.
} 
sobre o presidente o epíteto de "golpista", que ameaçava a "solidez das instituições" e corroía "a hierarquia militar". ${ }^{9}$

\section{Militares e partidos políticos}

A capacidade que o PTB teve de influenciar setores militares ou de interagir com eles foi, certamente, um dos principais fatores para a eclosão do golpe. ${ }^{10}$ (Maria Celina D’Araújo)

Esse texto levanta pelo menos duas questões relevantes para se pensar alguns elementos da experiência democrática vivida pelo Brasil nos anos Jango. A primeira delas diz respeito à importância dos partidos políticos naquele período, na contramão, portanto, de concepções que insistem na avaliação de que a estrutura partidária do sistema político brasileiro seria "inconsistente" e "frágil". Essa importância se traduziu, por exemplo, na filiação de militares - oficiais e subalternos - aos partidos, trazendo para dentro da caserna as disputas políticas, vale dizer, ideológicas e partidárias. Por isso mesmo, o Partido Trabalhista Brasileiro (PTB) e a União Democrática Nacional (UDN), representantes de correntes opostas do espectro político-partidário, foram os partidos que mais receberam as filiações de militares e que, por isso mesmo, sofreram o impacto dessas disputas.

Portanto, deve-se, sim, considerar a dinâmica político-partidária vigente à época como um elemento básico para a eclosão do golpe de 1964. De acordo com Jorge Ferreira e Angela de Castro Gomes, a estratégia de expansão das bases político-eleitorais do PTB teve como alvo os setores nacionalistas e reformistas das Forças Armadas. A pregação petebista atingiu especialmente os sargentos - o "povo em armas", como se definiam -, que não hesitavam em se declarar "janguistas" e "brizolistas" e que, em função da ambiguidade da Constituição, acabaram concorrendo, em 1962, para cargos eletivos no Executivo municipal e no Legislativo. No estado da Guanabara, o sargento

\footnotetext{
${ }^{9}$ Ver, entre outros, Jorge Ferreira e Angela de Castro Gomes, op. cit., p. 179-85.

${ }^{10}$ Maria Celina D’Araújo. "Raízes do golpe: ascensão e queda do PTB”. In: Gláucio Ary Soares \& Maria Celina D’Araújo (orgs.), 21 anos de regime militar: balanços e perspectivas, Rio de Janeiro, Editora FGV, 1994, p. 69.
} 
Antonio Garcia Filho foi o segundo mais votado da bancada federal eleita pela Aliança Socialista Trabalhista (PTB/PST), só perdendo para Leonel Brizola, que chegou a conquistar quase 270 mil votos em um eleitorado de um milhão de eleitores. Como foi analisada anteriormente, apesar da manifestação do STF contrária à elegibilidade dos sargentos, a reação de desobediência à posição do Supremo geraria uma grave crise político-militar com repercussão negativa na construção da democracia no Brasil.

Nas mesmas eleições de 1962, ainda na Guanabara, só que do lado da UDN, o general Danilo Nunes foi o recordista de votos para a Assembleia Legislativa da Guanabara. Os mais de 50 mil votos que recebeu representavam uma parte do eleitorado carioca que apoiava sua postura conservadora, profundamente pautada por um feroz anticomunismo. Essa posição radical o conduziu à eleição para o governo estadual em 1965, como candidato a vice-governador na chapa do udenista Flexa Ribeiro, derrotado nas urnas por Negrão de Lima, da aliança PTB/PSD.

É fácil observar que posições radicais, compartilhadas por setores militares, foram trazidas para dentro de partidos políticos como PTB e UDN, esvaziando, como ficou demonstrado pelos resultados eleitorais de 1962, o tradicional partido do centro, o Partido Social Democrático (PSD). ${ }^{11} \mathrm{Ou}$ seja, "as direitas, como as esquerdas, estavam dispostas a recorrer aos militares para alcançar seus projetos de poder". ${ }^{12}$ E completamos: esse recurso aos militares visava tanto à política de partidos, votos e eleições, quanto às iniciativas no campo revolucionário/golpista, de acordo com a linguagem da época.

\section{Jango e as veredas estreitas da negociação}

O desinteresse de Jango de buscar uma solução negociada para o impasse não pode ser contestado. ${ }^{13}$

(Marco Antonio Villa)

Não resta dúvida de que existe certo consenso em torno da avaliação de que o presidente Goulart foi um dos responsáveis pelo sucesso do golpe de 1964

\footnotetext{
${ }^{11}$ Ver Lucia Hippolito. De raposas e reformistas: o PSD e a experiência democrática brasileira (1945-64). Rio de Janeiro: Paz e Terra, 1985.

12 Ver Jorge Ferreira e Angela de Castro Gomes, op. cit., p. 136.

${ }^{13}$ Marco Antonio Villa. "Os gigolôs da memória”, O Globo, 8 de abril de 2014.
} 
em função de seu "desinteresse" ou de sua "incapacidade" de buscar uma "solução" - negociada ou não - para o impasse político-militar que se acirrou após o Comício de 13 de março, na Central do Brasil. ${ }^{14}$ A essa tese, junta-se uma outra: a de que o golpe e a consequente decretação da ditadura civil e militar já estavam escritos nas estrelas.

Na direção contrária, pretende-se aqui mostrar as múltiplas possibilidades de ação política existentes na segunda metade de 1963. Opções quase sempre assentadas no fio da navalha, cada vez mais estreitadas por escolhas e ações específicas que "solaparam as possibilidades de ampliação e consolidação de apoio para as reformas, e, desta forma, reduziram as oportunidades de implementar, sob regras democráticas, um compromisso sobre estas reformas", como analisa Argelina Figueiredo. ${ }^{15}$

Dentro do regime democrático, um cardápio de reformas estruturais, tal como apresentado por Goulart como mola central de seu projeto de sustentação política, necessita de um amplo apoio congressual. ${ }^{16}$ No entanto, Jango enfrentava desafios até mesmo dentro das forças de esquerda, que tinham seu próprio projeto de poder, tangenciando e até competindo com o dele. Leonel Brizola, Miguel Arraes, o PTB, o Partido Comunista, o movimento sindical e o movimento estudantil o pressionavam em várias direções, tendo em vista aquilo que melhor servia aos interesses de cada grupo.

O debate sobre a reforma agrária ao longo de 1963 e seu encaminhamento político-partidário até a votação do projeto no Congresso parecem ser um bom exemplo desse estreitamento dos caminhos da negociação liderada por Jango. O tom de radicalização surgiu logo em abril, mês da convenção nacional da UDN, quando Bocayuva Cunha, líder do PTB na Câmara dos Deputados, apresentou um projeto de emenda constitucional que alterava as formas de indenização das terras desapropriadas por interesse social. A

\footnotetext{
${ }^{14}$ Ver Jorge Ferreira. "O último ato: sexta-feira 13 na Central do Brasil". In: Jorge Ferreira; $O$ imaginário trabalhista, op. cit., p. 319-74.

${ }^{15}$ Argelina Figueiredo, citada em: Carlos Fico, Além do golpe. Rio de Janeiro, Record, 2004, p. 50.

${ }^{16}$ Sobre as reformas constitucionais do governo Fernando Henrique e a conquista do apoio parlamentar, ver: Helena Chagas. "Relações Executivo-Legislativo". In: Bolívar Lamounier \& Rubens Figueiredo (Orgs.); A Era FHC: um balanço. São Paulo, Cultura Editores Associados, 2002. p. 331-68.
} 
movimentação de Leonel Brizola nas cidades-satélites de Brasília, ameaçando com um levante popular, caso a reforma agrária não fosse aprovada, alarmou udenistas, pessedistas, e até petebistas moderados.

O governador da Guanabara, Carlos Lacerda, bastante conhecido por suas posições radicais de direita, ${ }^{17}$ botou lenha na fogueira e, na véspera da convenção nacional, ameaçou sair da UDN e renunciar ao seu mandato, caso os convencionais resolvessem apoiar a reforma pregada pelo PTB. Batendo de frente com o deputado udenista José Aparecido, que apresentou o manifesto da ala mais moderada com declaração de voto favorável à reforma agrária através de emenda constitucional, o governador carioca defendeu a "intocabilidade da Constituição". Analisando os objetivos da atitude de Lacerda, o jornalista Carlos Castello Branco profetizou: "Carlos Lacerda pretendeu assinalar uma posição radical no quadro geral da crise brasileira, que acredita acabará se impondo não só na UDN, como nos demais partidos do centro liberal e conservador" ${ }^{18}$

Em junho, foi a vez de o moderado PSD apresentar seu projeto de reforma agrária. Tímido em relação ao "programa máximo" de reformas apresentado pelas esquerdas, havia, no entanto, representado um avanço em relação, por exemplo, à caracterização do "latifúndio improdutivo", ou seja, o que tinha mais de $50 \%$ das terras sem cultivo. ${ }^{19}$

Ocupando a presidência da República, lugar privilegiado que o capacitava a liderar o entendimento em torno da reforma agrária "possível”, Goulart não conseguiu, no entanto, aglutinar o PTB em torno desse projeto mais moderado, nem impedir a radicalização do processo, talvez um efeito indesejado, mas, quem sabe, evitável. Incapaz de costurar um programa mais moderado e gradual a partir da composição PTB/PSD, Goulart optou por se aproximar dos grupos mais radicais de esquerda, ao apoiar as manifestações de rua com vistas a pressionar o Congresso a votar a reforma agrária. Dessa forma, os caminhos de negociação se afunilavam e se transformavam, cada vez mais, em estreitas veredas.

Jango, tampouco, teve sucesso em encaminhar a sua sucessão, o que lhe daria condições de sinalizar, para frente, um determinado projeto de país.

\footnotetext{
${ }^{17}$ Sobre Carlos Lacerda, ver, entre outros: Marly Silva da Motta. O Rio de Janeiro continua sendo: de cidade-capital a estado da Guanabara. Rio de Janeiro, Editora FGV, 2001.

18 Carlos Castello Branco, citado em Marly Silva da Motta, op. cit., p. 197.

19 Ver Jorge Ferreira e Angela de Castro Gomes, op. cit., p. 169-70.
} 
Prevista para outubro de 1965, a eleição presidencial, no entanto, já havia invadido os corações e as mentes dos principais postulantes ao cargo. Na já citada convenção da UDN, realizada em abril de 1963, o nome do radical Carlos Lacerda havia se sobressaído em relação ao moderado Magalhães Pinto, o qual, de maneira aparentemente contraditória, viria a ser a principal liderança civil do futuro golpe de 1964. Indicado como favorito pelas pesquisas, destacava-se o nome de Juscelino Kubitschek, que contava voltar à presidência: dessa vez, não para o Catete, e sim para o Alvorada, que ele havia construído na Novacap. ${ }^{20}$ Tal como nas negociações para a aprovação de uma reforma agrária moderada, a composição PTB/PSD, que havia rendido frutos em 1955, com a vitória da chapa JK/Jango, fracassou no intuito de apoiar Juscelino Kubitschek em sua pretensão de voltar à presidência em 1965.

Pode-se atribuir esse fracasso, em grande medida, ao ambiente de radicalização política que, sobretudo a partir do final de 1963, exacerbou a percepção, por parte dos principais atores políticos, de que a resolução dos conflitos poderia ser encontrada não apenas na disputa eleitoral, ou seja, dentro dos quadros da normalidade institucional. É nesse contexto que tanto as esquerdas como as direitas fazem suas apostas, ao mesmo tempo, nas eleições presidenciais de 1965 e em soluções extrainstitucionais, definidas por expressões conhecidas, como "na marra" ou "intervenção redentora".

Se não chegou a ficar paralisado, o presidente se mostrou incapaz de manter a capa de conciliador e de fiador do sistema democrático. A mudança na posição da imprensa em relação ao governo Jango contribuiu fortemente para o estreitamento dos canais de negociação e, por consequência, para o isolamento do presidente, a quem restaram poucas opções de saída para o impasse político que se agravava rapidamente. Em outubro de 1963, não por acaso logo depois da rebelião dos sargentos, proprietários de jornais e rádios da Guanabara formaram a Rede da Democracia, composta pelo O Globo, Jornal do Brasil e Rádio Tupi. Gradativamente, a bandeira da democracia, até então empunhada pelo governo legalmente eleito e empossado em 1961, seria tomada pelos conservadores, que receberam o apoio de parlamentares de centro, como os pessedistas Tancredo Neves e Ulysses Guimarães. ${ }^{21}$

\footnotetext{
${ }^{20}$ Ver Jorge Ferreira e Angela de Castro Gomes, op. cit., p. 198-99.

${ }^{21}$ Idem, Ib., p. 217.
} 
Se é possível contestar a ideia de que Jango não se interessava pela negociação política, pode-se, no entanto, indagar se ele teria sido um "bom negociador", que acabou derrotado pela força das armas. A resposta parece estar na postulação de uma série de questões sobre o padrão de negociação posto em ação pelo presidente. Teria sido esse padrão inadequado em um contexto de radicalização e, sobretudo, de rápida mudança de cenário como resultado da crise política? Jango não teria se apercebido da gravidade da crise? Ou, então, não possuiria instrumentos para nela intervir, e impedir que uma coalizão de forças de oposição se construísse? Será que sua falta de experiência de liderar a reação legalista de 1961 poderia explicar a falta de coordenação nas ações do governo diante da iminência de um golpe militar?

\section{Cartas na mesa}

Jango foi deposto pela carta golpista que estava nas mãos de vários jogadores, mas a direita fez a canastra. ${ }^{22}$

(Elio Gaspari)

A imagem de um jogo de apostas é bem ilustrativa da situação política do país, especialmente depois do Comício da Central do Brasil. Se a avaliação de Miguel Arraes, então governador de Pernambuco, de que "um golpe virá: de cá ou de lá”, parece reforçar a análise de Gaspari citada, deve-se lembrar que nem todos os jogadores dispunham da "carta golpista”. É o caso, por exemplo, do ex-presidente Kubitschek, para quem a radicalização trazia a necessidade de fortalecer o "centro" e torná-lo viável eleitoralmente. Havia ainda aqueles, como Carlos Lacerda, que podiam acender uma vela a Deus disputa eleitoral -, e outra ao diabo, a deposição do presidente com o apoio militar.

Pode-se perceber, portanto, um duplo movimento que, por um lado, procurava qualificar o conceito de democracia como o regime que deveria visar a eliminar os privilégios de uma minoria. Nesse sentido, democracia, por si mesmo, não bastava; seria necessário agregar-lhe o termo popular. Foram

${ }^{22}$ Elio Gaspari, "1964...2014”, o Globo, 26 de março de 2014. 
várias as propostas de democracia popular expostas no Comício da Central, apontando a inviabilidade do aparato constitucional e congressual vigente em atender os interesses da maioria da população.

Ao mesmo tempo, dois dias depois do Comício da Central, em 15 de março, Jango enviou uma Mensagem ao Congresso Nacional, em que pregava a necessidade de uma reforma eleitoral. Um de seus pontos centrais era a ampliação do eleitorado, com a extensão do voto aos analfabetos e aos praças e sargentos das Forças Armadas. O mais delicado, porém, foi a introdução da expressão "são elegíveis os alistáveis", o que, na prática, permitiria que Brizola, cunhado do presidente, pudesse se candidatar em 1965, e, mais preocupante, abriria caminho para a possibilidade de reeleição de Jango. A entrada na disputa eleitoral desses dois fortes candidatos, não previstos até aquele momento, assustou não apenas o PSD e a UDN, como o próprio PTB, que tinha em Miguel Arraes um postulante de peso à corrida presidencial.

As apostas no processo eleitoral, às vésperas do golpe, demonstram que a saída dentro das regras do jogo ainda constava do leque de opções de alguns dos principais atores do cenário político daquele momento. No entanto, em um ambiente de grande incerteza, a visão de longo prazo se torna refém do imediatismo, como foi bem analisado por Jorge Ferreira e Angela de Castro Gomes:

(...) medidas de grande e longo alcance, que transformariam o grau de inclusão da democracia brasileira, como o voto aos analfabetos, perderam tal sentido, ficando aprisionadas pelas circunstâncias eleitorais e pelas disputas políticas imediatas e radicais que dominavam o tenso cenário de março de $1964 .{ }^{23}$

Sabemos o epílogo desse filme, e nele a democracia foi a maior vítima. Em suas cenas finais, é possível notar que, no movimento golpista, houve uma ativa participação de líderes civis de oposição ao governo, dentre os quais se destacaram os governadores dos estados mais fortes da federação: São Paulo (Ademar de Barros); Minas Gerais (Magalhães Pinto) e Guanabara (Carlos Lacerda). Foi, portanto, um golpe civil e militar. Pode-se até afirmar que a atuação desses políticos levou sempre em conta, ao lado das disputas com

${ }^{23}$ Ver Jorge Ferreira e Angela de Castro Gomes, op. cit., p. 289. 
vistas às eleições de 1965, a antecipação compulsória do mandato de Jango, ou seja, sua deposição. Com o apoio militar, é claro.

Acompanhando o "movimento em marcha", ${ }^{24}$ observa-se que Magalhães Pinto, o até então "moderado" governador de Minas, pagou para ver e se apresentou como a "liderança civil" do movimento que visava a depor o presidente, ao se articular com o general Olympio Mourão Filho que, de Juiz de Fora, havia se deslocado para a Guanabara à frente de um comboio militar. Enquanto isso, na Guanabara, ex-capital federal e principal centro político do país, o governador Lacerda e o grupo de militares liderado por Castello Branco, então chefe do Estado-Maior do Exército, acabaram sendo ultrapassados pela investida de um governador moderado e de um general considerado meio "desequilibrado"..$^{25}$

Vitorioso o golpe de 64, o noticiário especulava se seria a repetição da intervenção militar de outubro de 1945, que havia acabado com a ditadura do Estado Novo e restaurado a institucionalidade democrática no país. As expectativas de muitos eram de que, afastado o alegado perigo da "comunização" do país, o regime democrático seria "aperfeiçoado". A questão era que "democracia" seria essa e que tipo de "aperfeiçoamento" seria então necessário.

Renova-se aqui a advertência de que os rumos que acabariam levando à falência da democracia não estavam dados na partida do movimento vitorioso; não se inscreveriam, portanto, em uma crônica de morte anunciada. De certa maneira, a questão democrática esteve presente nos debates travados logo após a vitória das forças golpistas. Percebe-se, por exemplo, a preocupação com o uso da palavra mais adequada para designar o ocorrido: havia sido "golpe" ou "revolução" o que ocorrera em 1ํ de abril de 1964, quando o presidente eleito fora deposto? A primeira - "golpe" - foi sumariamente rejeitada pelos civis e militares que comandaram o movimento vitorioso. Eles preferiram "revolução, vitoriosa e legítima por si mesma", como proclamaram no Ato Institucional de 9 de abril. Já "revolução", mesmo associada a movimentos vitoriosos de esquerda no mundo, foi assumida de imediato pelos autoproclamados "revolucionários de 64 ". Nesse último caso, seria uma possível comparação com as "quarteladas" ocorridas nos países

\footnotetext{
${ }^{24}$ Ver Jorge Ferreira e Angela de Castro Gomes, op. cit., cap. 21.

${ }^{25}$ Citado em Jorge Ferreira e Angela de Castro Gomes, op. cit., p. 336
} 
sul-americanos vizinhos? Ou uma referência à Revolução de 1930, ainda muito forte no imaginário nacional como um momento de ruptura com um passado, a denominada "República Velha"?

Havia muita incerteza em relação ao padrão de atuação política a ser seguido pelos golpistas, civis e militares, de 64. A imprevisibilidade era grande, já que existe hoje um consenso de que não haveria, então, um projeto definido para depois da tomada do poder. É interessante lembrar que o presidente da Câmara, Ranieri Mazzilli, empossado como presidente da República a partir da vacância do cargo decretada pelo presidente do Senado, Auro de Moura Andrade, chegou a indicar, no dia 3 de abril, alguns componentes de seu ministério. Não por acaso, alguns deles viriam, posteriormente, a ser referendados pelo próximo presidente, general Castello Branco. ${ }^{26}$

A busca desse clima de "normalidade institucional" parece ter sido inspirada no golpe que derrubou Vargas do poder, em outubro de 1945, quando o presidente do STF assumiu a presidência da República até a eleição do general Dutra, em dezembro. Dessa vez, no entanto, seria diferente, e logo o noticiário apontava a preferência pelo general Castello Branco, então chefe do Estado-Maior do Exército, para completar o mandato de Goulart até 31 de janeiro de 1966. Preferência que não era unanimidade, tal como evidenciado pelas especulações em torno de outros nomes que competiriam com o de Castello. É interessante verificar que, até o dia 7 de abril, conforme registrado em $O$ Globo, caberia ao presidente Mazzilli "unificar o ponto de vista dos chefes militares", já que havia o perigo de um temido "pronunciamento" dos generais vencedores do dito "movimento revolucionário". A justificativa do jornal, amplamente favorável ao golpe, foi a de que essa "unificação visa principalmente a permitir que o poder civil possa funcionar paralelamente ao militar". ${ }^{27}$ Três dias depois, em 10 de abril, $O$ Globo anunciava, em manchete de primeira página, que o "General Kruel também desiste de sua candidatura". No dia seguinte, Castello foi eleito pelo Congresso Nacional, e tomou posse no dia 15 .

\footnotetext{
${ }^{26}$ Ver O Globo, 03 de abril de 1964. São eles: General Artur da Costa e Silva (Guerra); Octavio Gouvêa de Bulhões (Fazenda); Arnaldo Sussekind (Trabalho); Vasco Leitão da Cunha (Exterior).

${ }^{27}$ O Globo, 08 de abril de 1964.
} 
Se as feições peculiares do regime democrático entre 1946 e 1964 tiveram um papel crucial na vitória do golpe que encerrou o regime democrático no país, é verdade também que influenciaram na definição dos caminhos por onde trilharia a ditadura por mais de duas décadas. Mas isso é assunto para outro texto.

\section{Referências}

CASTRO, Celso; D’ARAúJ0, Maria Celina; SOARES, Gláucio Ary Dillon.

(1995). A volta aos quartéis: a memória militar sobre a ditadura. Rio de Janeiro, Editora FGV.

CHAGAS, Helena.

(2002). "Relações Executivo-Legislativo". In: Bolívar Lamounier; Rubens Figueiredo (Orgs.); A Era FHC: um balanço. São Paulo, Cultura Editores Associados.

D'ARAÚJ0, Maria Celina.

(1994). “Raízes do golpe: ascensão e queda do PTB". In: Gláucio Ary Dillon Soares; e Maria Celina D’Araújo (Orgs.); 21 anos de regime militar: balanços e perspectivas. Rio de Janeiro, Editora FGV.

FERREIRA, Jorge; GOMES, Angela de Castro. (2014). 1964: o golpe que derrubou um presidente, pôs fim ao regime democrático e instituiu a ditadura no Brasil. Rio de Janeiro, Civilização Brasileira.

(2005). “A legalidade traída: os dias sombrios de agosto e setembro de 1964". In: Jorge Ferreira (0rg.); 0 imaginário trabalhista. Rio de Janeiro, Civilização Brasileira.

(2005). “0 último ato: sexta-feira 13 na Central do Brasil". In: Jorge Ferreira (Org.); o imaginário trabalhista. Rio de Janeiro, Civilização Brasileira.
FICO, Carlos.

(2004). Além do golpe. Rio de Janeiro, Record.

HIPPOLITO Lucia.

(1985). De raposas e reformistas: o PSD e a experiência democrática brasileira (194564). Rio de Janeiro, Paz e Terra.

MOTTA, Marly Silva.

(2001). O Rio de Janeiro continua sendo: de cidade-capital a estado da Guanabara. Rio de Janeiro, Editora FGV.

PARUCKER, Paulo.

(1992). Praças em pé de guerra. 0 movimento político dos subalternos militares no Brasil, 1961-64. Dissertação de mestrado defendida no Programa de Pós-graduação em História (PPGH) da Universidade Federal Fluminense (UFF). Niterói, Rio de Janeiro.

\section{Recebido em}

abril de 2014

\section{Aprovado em}

agosto de 2014 